\title{
Deletion of Nedd4-2 results in progressive kidney disease in mice
}

\author{
Tanya L Henshall ${ }^{1,4}$, Jantina A Manning ${ }^{1,4}$, Omri S Alfassy ${ }^{1,4}$, Pranay Goel ${ }^{1,2,4}$, Natasha A Boase ${ }^{1}$, Hiroshi Kawabe ${ }^{3}$ and \\ Sharad Kumar ${ }^{*, 1,2}$
}

NEDD4-2 (NEDD4L), a ubiquitin protein ligase of the Nedd4 family, is a key regulator of cell surface expression and activity of the amiloride-sensitive epithelial $\mathrm{Na}^{+}$channel (ENaC). While hypomorphic alleles of Nedd4-2 in mice show salt-sensitive hypertension, complete knockout results in pulmonary distress and perinatal lethality due to increased cell surface levels of ENaC. We now show that Nedd4-2 deficiency in mice also results in an unexpected progressive kidney injury phenotype associated with elevated ENaC and $\mathrm{Na}^{+} \mathrm{Cl}^{-}$cotransporter expression, increased $\mathrm{Na}^{+}$reabsorption, hypertension and markedly reduced levels of aldosterone. The observed nephropathy is characterized by fibrosis, tubule epithelial cell apoptosis, dilated/cystic tubules, elevated expression of kidney injury markers and immune cell infiltration, characteristics reminiscent of human chronic kidney disease. Importantly, we demonstrate that the extent of kidney injury can be partially therapeutically ameliorated in mice with nephron-specific deletions of Nedd4-2 by blocking $\mathrm{ENaC}$ with amiloride. These results suggest that increased $\mathrm{Na}^{+}$reabsorption via $\mathrm{ENaC}$ causes kidney injury and establish a novel role of NEDD4-2 in preventing $\mathrm{Na}^{+}$-induced nephropathy. Contrary to some recent reports, our data also indicate that ENaC is the primary in vivo target of NEDD4-2 and that Nedd4-2 deletion is associated with hypertension on a normal $\mathrm{Na}^{+}$diet. These findings provide further insight into the critical function of NEDD4-2 in renal pathophysiology.

Cell Death and Differentiation (2017) 24, 2150-2160; doi:10.1038/cdd.2017.137; published online 1 September 2017

$\mathrm{Na}^{+}$homeostasis in the kidney is critical for the maintenance of blood volume and blood pressure (BP). The $\mathrm{Na}^{+}$reabsorption in the nephron is mediated via the $\mathrm{Na}^{+} \mathrm{Cl}^{-}$co-transporter (NCC) in the distal convoluted tubule (DCT), and through the amiloride-sensitive epithelial $\mathrm{Na}^{+}$channel $(\mathrm{ENaC})$ in the connecting tubule (CNT), distal tubule (DCT) and the collecting duct (CD). Both NCC and ENaC are regulated by the ubiquitin protein ligase, NEDD4-2. ${ }^{1-5}$ Although NEDD4-2 is known to ubiquitinate and regulate the expression of many cell surface proteins, the most studied targets of NEDD4-2 are the three subunits $(a, \beta$ and $\gamma$ ) of ENaC. The WW domains of NEDD4-2 have been demonstrated to directly bind to the PPxY motifs present in the cytoplasmic $C$ termini of all three $\mathrm{ENaC}$ subunits leading to their ubiquitination, endocytosis and degradation. ${ }^{2,3}$ Thus, an expected consequence of the loss of Nedd4-2 is increased cell surface expression and membrane retention of $\mathrm{ENaC}$, resulting in increased $\mathrm{ENaC}$ activity. ${ }^{1}$ The significance of NEDD4-2-dependent regulation of ENaC in the maintenance of $\mathrm{Na}^{+}$homeostasis is apparent from Liddle's syndrome, characterized by constitutively elevated $\mathrm{ENaC}$ activity and hypertension due to mutations in the PY motifs of $\beta$ - and $\gamma$-ENaC, which abrogate the interaction between $\mathrm{ENaC}$ and NEDD4-2. ${ }^{2}$

NEDD4-2 is widely expressed during mouse development and in adult tissues, with particularly high expression in the liver, kidney, heart, brain and lung. ${ }^{1,6}$ The studies of Nedd4-2 knockout (KO) mice have provided useful and also somewhat unexpected and contradictory insights into the in vivo function of NEDD4-2. A Nedd4-2 KO mouse line (Nedd4-2 $\Delta$ exons $6-8$, which includes an alternative translation start site and WW domain 1) express small amounts of Nedd4-2 splicing isoforms. ${ }^{7}$ These mice appear normal but show slightly increased $\mathrm{ENaC}$ expression and hypertension upon feeding a high-salt diet. ${ }^{7}$ A renal-tubule-specific Nedd4-2 conditional KO mouse with the same mutation (Nedd $4 L^{\text {Pax } 8 / L C 1}$ ) demonstrated that hypertension is largely due to increased expression and activity of the NCC. ${ }^{8}$ Recently, it was shown that $\alpha$ and $\gamma$ (but not $\beta$ ) $\mathrm{ENaC}$ levels are increased when these mice are fed a long-term, low $\mathrm{K}^{+}$diet. $^{9}$

A KO line generated in our laboratory in which all Nedd4-2 splicing variants are absent (Nedd4-2 $\Delta$ exons 15-16) display increased $\mathrm{ENaC}$ expression in the lung and kidney, with perinatal death of animals due to respiratory distress as a result of failure of lungs to inflate, or severe sterile inflammation of the lung. ${ }^{5}$ The different severity of the phenotypes between these lines is likely due to the hypomorphic nature of the Nedd4-2 $\Delta$ exons $6-8$ allele. This is supported by studies with another independent line where Nedd4-2 KO results in perinatal death, ${ }^{10}$ and a conditional KO of Nedd4-2 in the lung that was found to be sufficient for animals to develop inflammatory lung disease, leading to perinatal lethality. ${ }^{10}$

To determine the effect of Nedd4-2 loss in the kidney, we analyzed the pathology of Nedd4-2 $\Delta$ exons 15-16 mice. We report here that Nedd4-2 loss results in progressive kidney damage beginning immediately after birth. Additionally, we confirm this pathology in a kidney tubule-specific Nedd4-2 KO

${ }^{1}$ Centre for Cancer Biology, University of South Australia and SA Pathology, Adelaide, SA 5000, Australia; ${ }^{2}$ School of Medicine, University of Adelaide, Adelaide, SA 5005, Australia and ${ }^{3}$ Max Planck Institute of Experimental Medicine, Department of Molecular Neurobiology, Göttingen 37075, Germany

${ }^{*}$ Corresponding author: S Kumar, Centre for Cancer Biology, University of South Australia and SA Pathology, Frome Road, PO Box 14, Rundle Mall, Adelaide, SA 5000, Australia. Tel: +61 88222 3738; Fax: +61 88222 3139; E-mail Sharad.Kumar@unisa.edu.au

${ }^{4}$ These authors contributed equally to this work.

Received 07.6.17; revised 05.7.17; accepted 19.7.17; Edited by G Melino; published online 01.9.17 
mouse line, Nedd4-2 ${ }^{K s p 1.3}$. We further show that increased ENaC activity contributes to the observed kidney damage.

We therefore provide the first evidence that loss of Nedd4-2 results in early and progressive kidney damage. Given our demonstration of a direct and critical role for $\mathrm{ENaC}$ in renal injury, our Nedd4-2 KO mice can be a valuable resource for the study of the effects of salt on progression of kidney damage.

\section{Results}

Nedd4-2/- kidney pathology consistent with kidney damage. We have previously described a perinatal lethal phenotype of Nedd4-2-/- mice due to respiratory distress; however, a small percentage of animals survive up to 3 weeks of age. ${ }^{5}$ To determine the role of NEDD4-2 in the kidney, we carried out pathological analysis of kidneys from wild-type and surviving Nedd4-2 ${ }^{-/}$mice at postnatal $(P)$ day 20. Kidneys from Nedd4-2-/- mice appeared pale and showed histological changes consistent with renal damage, including a disorganized structure and numerous cortical cysts with necrotic cellular debris, often with luminal stenosis/obstruction (Figure 1a). Large areas of mesenchyme were observed by histology, immunohistochemistry and real-time quantitative PCR (qRT-PCR) for the mesenchymal marker, vimentin (Figures $1 \mathrm{~b}$ and $\mathrm{c}$ ). In addition, Nedd4-2 ${ }^{-/}$kidneys showed obvious fibrotic damage occupying a large portion of the cortex revealed by immunohistochemistry and qRT-PCR for $a-1$ type 1 collagen. Consistent with kidney injury, expression of the myofibroblast marker, $a$-smooth muscle actin (SMA), and marker for proximal tubule kidney injury, kidney injury molecule-1 (KIM-1, also referred to as T-cell immunoglobulin mucin (TIM-1), ${ }^{11}$ was upregulated in Nedd4- $2^{-/}$kidneys compared with wild type at P20 (Figures $1 \mathrm{~b}$ and c).

Time-course analysis revealed normal kidney histology at embryonic day (E) 18.5, with damage becoming evident by P3 and progressing in severity until death at P20 (Supplementary Figure 1). The lack of kidney pathology at E18.5 suggests that kidney development occurs normally in Nedd42-deficient mice.

Generation of renal-tubule-specific Nedd4-2-deficient mice. After identifying a critical new role for NEDD4-2 in renal homeostasis, we next aimed to investigate the progression of kidney injury beyond 20 days. To this end, we generated a renal-tubule-specific Nedd4-2 KO mouse line by crossing a previously generated Nedd4- $2^{\mathrm{fl} / \mathrm{fl}}$ mouse line (with ablation of Nedd4-2 exon 15 onward, resulting in the absence of the catalytic HECT domain and a complete loss of Nedd4-2 protein) ${ }^{10}$ to the Ksp1.3-Cre transgene line. ${ }^{12}$ Ksp-cadherin, also called cadherin-16, has a well-characterized, kidney-specific expression in renal epithelial cells of the collecting ducts, loop of Henle, the majority of proximal tubules and in some distal tubules. ${ }^{13}$ Therefore, Ksp1.3-Cre; Nedd4- $2^{\mathrm{fl} / f l}$ blocks NEDD4-2 expression in cadherin-16positive cells and is hereafter referred to as Nedd4-2 $2^{K s p 1.3}$. Immunoblot analysis of whole kidney lysates from this strain showed a decrease in NEDD4-2 protein compared with control kidneys (Cre negative) at P40 (Figure 2a). This was quantitated to an average reduction of $\sim 50 \%$ (Figure $2 b$ ).
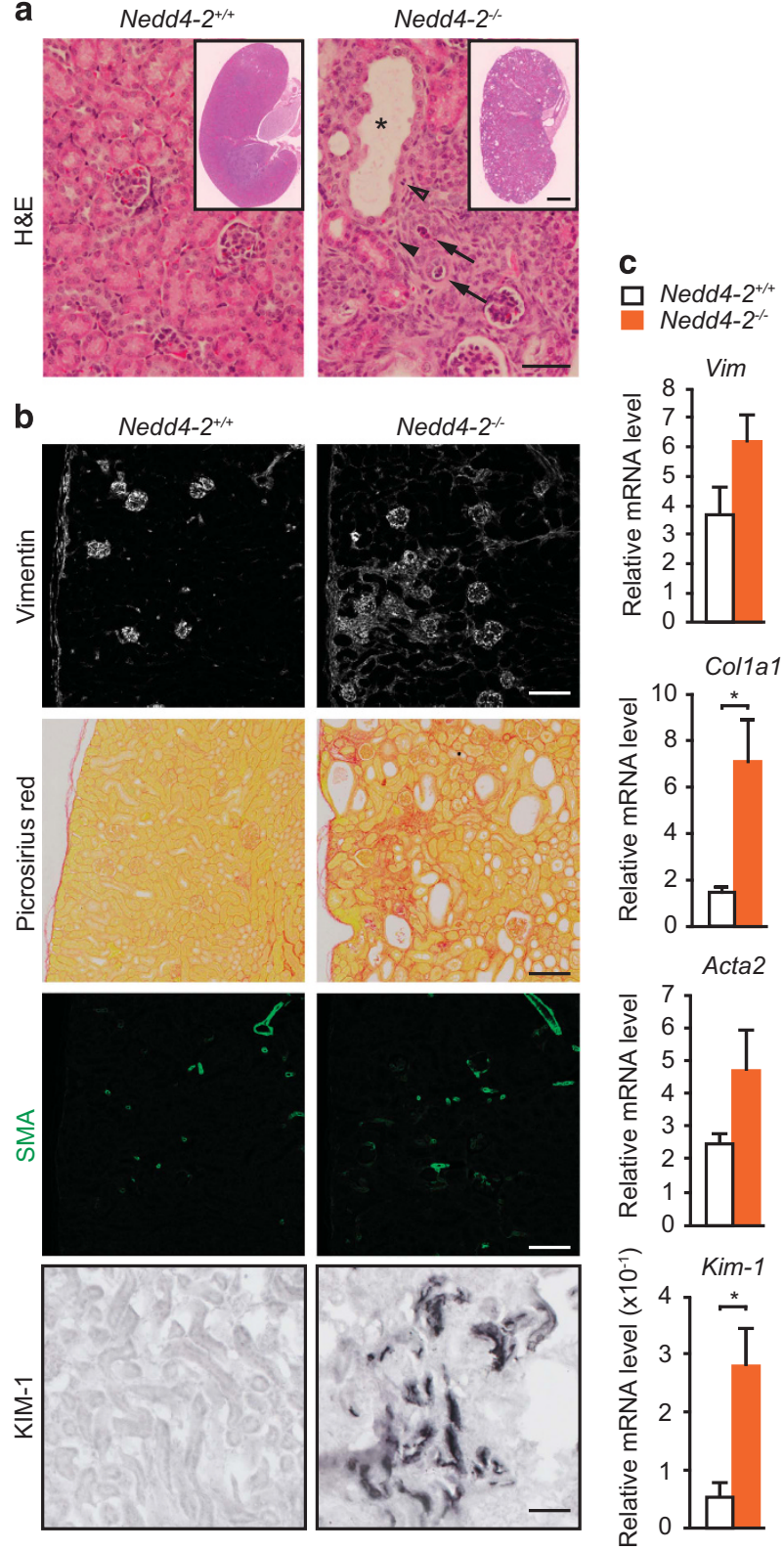

Figure 1 Loss of NEDD4-2 results in kidney injury in juvenile mice. (a) Representative images showing hematoxylin-eosin (H\&E) staining. Pathological observations include enlarged tubules (*), cellular debris within tubules (arrows) and mesenchyme infiltration (arrowheads). (b) Immunostaining shows increased expression of vimentin (mesenchymal marker), (SMA; myofibroblasts) and KIM-1 (marker of proximal tubule kidney injury). Picrosirius red staining demonstrates fibrosis in Nedd4-2 $2^{-1}$ kidneys. (c) Increased gene expression for markers of kidney pathology, including collagen (encoded by Col1a1), vimentin (Vim), SMA (Acta2) and Kim-1, as determined by qRT-PCR in Nedd4-2 $2^{+/+}$or Nedd4-2 ${ }^{-/-}$mice. Data are normalized to tbp levels and represent mean \pm S.E.M. for four mice per genotype. ${ }^{*} P<0.05$. Scale bars: $(\mathbf{a})=50 \mu \mathrm{m}$, inset $=1 \mathrm{~mm}$; (b) (vimentin, picrosirius red and $\mathrm{SMA})=100 \mu \mathrm{m},(\mathrm{KIM}-1)=50 \mu \mathrm{m}$

Remaining NEDD4-2 is likely due to expression within the glomerulus, blood vessels and any other cells that do not express cadherin-16, but express NEDD4-2. ${ }^{12,13}$ Immunohistochemical staining of control kidneys demonstrated high 
a

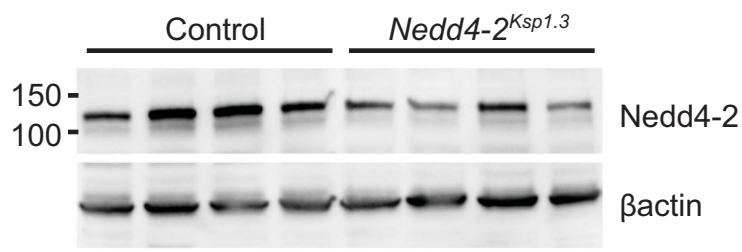

b

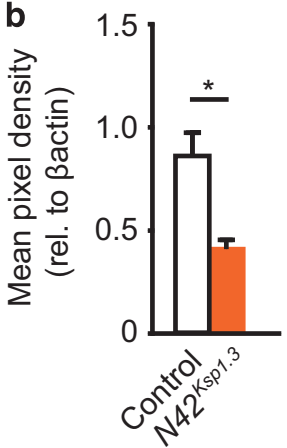

C Nedd4-2/DBA

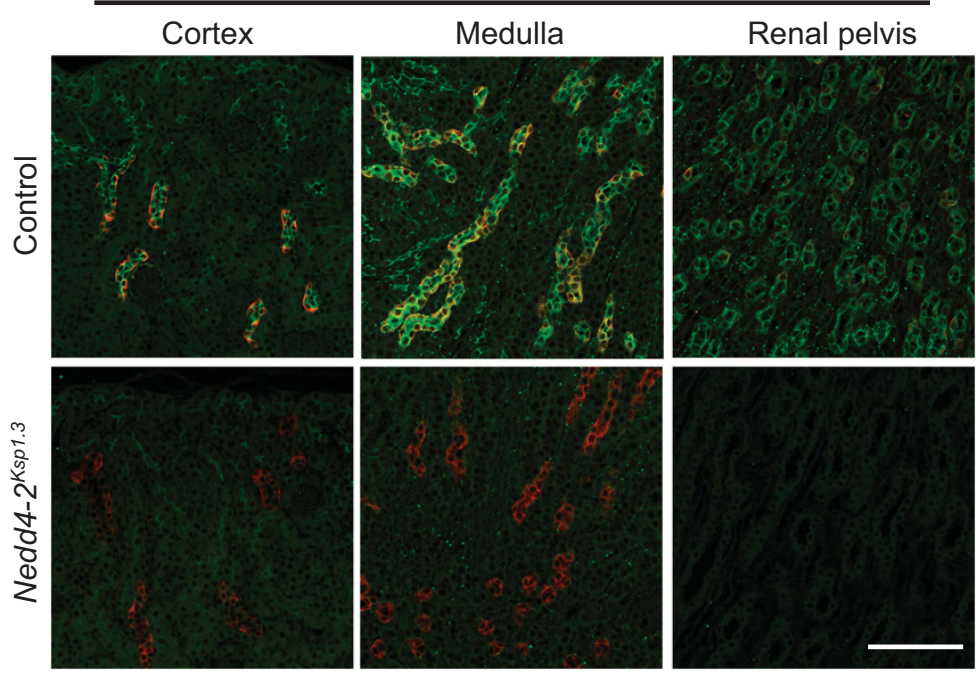

Figure 2 Generation of the renal-tubule-specific Nedd4-2 KO mice. (a) Semiquantitative immunoblot showing reduced NEDD4-2 expression in Nedd4-2 ${ }^{K s p 1.3}$ versus control mice at P40. Quantitated in (b) relative to $\beta$-actin expression to show an average reduction of $\sim 50 \%$ with remaining NEDD4-2 likely due to expression within the renal corpuscle, blood vessels and any other cells that do not express cadherin-16 but express NEDD4-2. ${ }^{12,13}$ (c) Immunohistochemical staining demonstrated high NEDD4-2 (green) expression within the distal nephron of control mice, including the collecting ducts as indicated by overlapping expression with the lectin marker, DBA (red). Importantly, NEDD4-2 expression was completely abolished in the distal renal tubule of Nedd4- $2^{K s p 1.3}$ kidneys. Scale bars: (c) $=50 \mu \mathrm{m}$. ${ }^{\star} P<0.05$

NEDD4-2 expression within the distal nephron including the collecting ducts, indicated by overlapping expression with the lectin marker, dolichos biflorus agglutinin (DBA) (Figure 2c). Importantly, NEDD4-2 expression was completely abolished in the distal renal tubule of Nedd4-2 $2^{K s p 1.3}$ kidneys.

\section{Nedd4-2 ablation in renal tubules leads to renal pathol-} ogy. Nedd4-2 $2^{K s p 1.3}$ revealed a similar progressive renal pathology to the global Nedd4-2 ${ }^{-1-}$ mice, with a slightly later onset. Macroscopic analysis revealed only minor differences between control and Nedd4-2 $2^{K s p 1.3}$ kidneys at P20 progressing to mild changes at P40 evident by an irregular border and small areas of disorganized tissue (Figure 3a). At 6 months, the kidneys appeared pale with small cysts in the cortex and a hydronephrotic renal pelvis. Histological staining showed increased tissue disorganization, tubule enlargement and fibrosis, starting from small isolated regions at P20 to larger fibrotic regions radiating in from the cortex at 6 months (Figure 3b). Closer analysis of Nedd4-2 $2^{K s p 1.3}$ mice at P40 showed enlarged tubules, with thinning or hypercellular epithelium, necrotic cellular debris and significant collagen deposition throughout the cortex and medulla as visualized by picrosirius red staining (Figures $4 \mathrm{a}$ and $\mathrm{b}$ ). Consistent with this result, mRNA levels of Col1a1 were higher in Nedd4-2 $2^{K s p 1.3}$ mice (Figures $4 d$ ). Similar to the Nedd4-2-/mice, vimentin, SMA and $\mathrm{KIM}-1$ expression were also increased demonstrating kidney injury (Figures 4c and $\mathrm{d}$ and Supplementary Figure 2). Immune cell infiltration was apparent in the Nedd4-2 ${ }^{K s p 1.3}$ kidney parenchyma, as seen by immunostaining for the T-lymphocyte marker, CD3 (Figures $4 \mathrm{e}$ and f).

Active caspase-3 staining was used to determine whether tubule epithelial cells were undergoing apoptosis. Figures $4 \mathrm{~g}$ and $h$ show a significant increase in the number of cleaved caspase-3-positive cells in Nedd4-2 $2^{K s p 1.3}$ kidneys compared with controls. Apoptotic cells were evident lining the tubules and also accumulating in the enlarged tubular lumens, detectable as early as P20 (Supplementary Figures 3a and $b$ ). In addition, some tubular epithelial cells also appeared swollen with enlarged nuclei, indicating necrotic changes to the lining epithelium in the absence of NEDD4-2 (Supplementary Figure 3c). Loss of tubule epithelial cells at an early age indicates that this may be an early manifestation of the renal disease. 
b

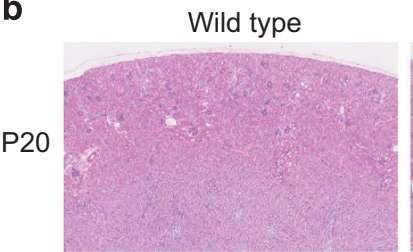

a
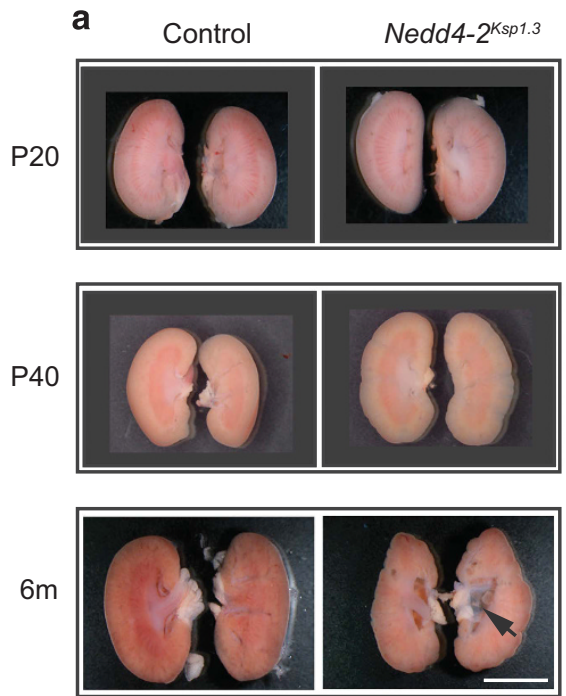

Control

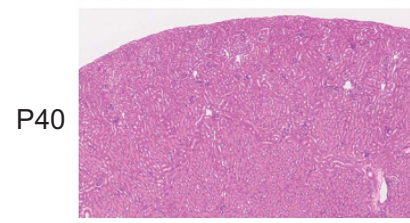

$6 m$

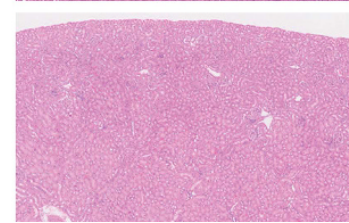

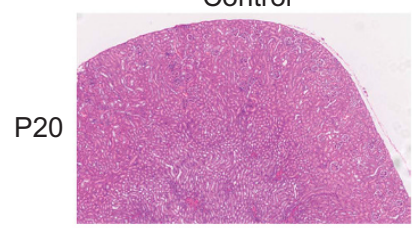

Nedd4-2-1-

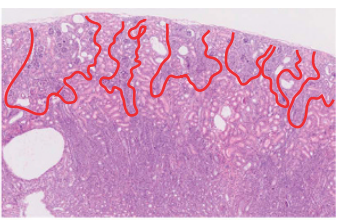

Nedd4-2Ksp1.3
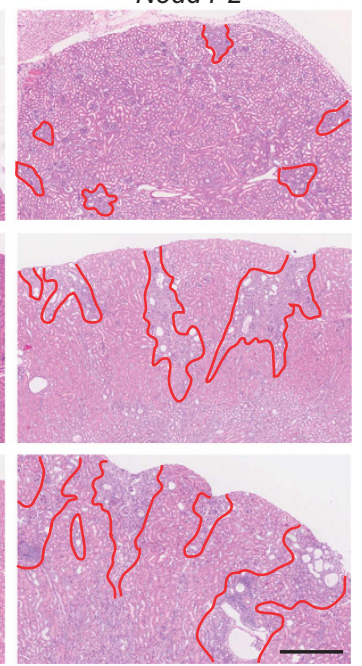

Figure 3 Disease progression in Nedd4-2 $2^{K s p 1.3}$ mice compared with Nedd4-2 $2^{-/-}$and control mice. (a) Macroscopic images of Nedd4-2 $2^{K s p 1.3}$ kidneys at P20, 40 and 6 months show disease progression. Indentations in the cortex are obvious at P40 and 6 months, and hydronephrosis develops only by 6 months (arrow). (b) Hematoxylin-eosin (H\&E) shows regions of kidney damage in Nedd4-2-/- kidneys at P20, compared with time course of disease progression in Nedd4- $2^{\text {Ksp1.3 }}$ kidneys (areas of damage are outlined in red). Scale bars: $(\mathbf{a})=5 \mu \mathrm{m}$ and $(\mathbf{b})=500 \mu \mathrm{m}$

Nedd4-2 deficiency leads to increased expression of ENaC and NCC. We next wanted to determine whether the levels of ENaC and NCC are altered in Nedd4-2 $2^{K s p 1.3}$ kidneys and could contribute to the renal disease observed in Nedd42-deficient animals. During the process of maturation, all three subunits of $\mathrm{ENaC}(a, \beta$ and $\gamma$ ) are post-translationally modified. The $a$ and $\gamma$ subunits are processed by proteolytic cleavage to their mature forms, and the $\beta$-subunit undergoes glycoprotein processing. ${ }^{14,15}$ It is the mature ENaC complexes that are predominantly localized at the plasma membrane where they are regulated by NEDD4-2. ${ }^{16}$ Immunostaining of Nedd4-2 $2^{K s p 1.3}$ kidneys at P40 demonstrated increased expression of all three ENaC subunits in the collecting ducts (Figures 5a). Semiquantitative analysis by immunoblot demonstrated upregulation of the mature forms of the ENaC subunits, and no change in the levels of the fulllength, unprocessed forms, indicating that the loss of NEDD4-2 expression in renal tubules results in increased levels of mature $\mathrm{ENaC}$ at the plasma membrane (Figures $5 \mathrm{~b}$ and c). Interestingly, cells with high ENaC expression could be seen lining dilated tubules and accumulating within the lumens (Figures 5d).

We next examined the levels of NCC in Nedd4-2 $2^{K s p 1.3}$ kidneys at P40. Immunostaining indicated higher levels of NCC protein in Nedd4-2 $2^{K s p 1.3}$ kidneys compared with control (Figures $5 \mathrm{e}$ and f). Immunoblot analysis of Nedd4-2 $2^{K s p 1.3}$ whole kidney lysates showed a similar increase in NCC expression (Figures $5 \mathrm{~g}$ and $\mathrm{h}$ ), confirming previous findings that NCC is regulated by NEDD4-2. ${ }^{4}$
Increased BP and salt reabsorption in Nedd4-2 ${ }^{K s p 1.3}$ mice. Nedd4-2 $2^{K s p 1.3}$ mice had increased blood $\mathrm{Na}^{+}$concentration, reduced blood $\mathrm{K}^{+}$concentration and increased $\mathrm{K}^{+}$ excretion on a standard laboratory diet (Table 1), which has not been previously observed in other Nedd4-2 KO models, even on a high-salt diet. ${ }^{7,8} \mathrm{Nedd} 4-2^{K s p 1.3}$ mice also produced more urine with a significantly lower osmolarity than their control counterparts, possibly as a result of the increased $\mathrm{Na}^{+}$ reabsorption. Glomerular filtration rate (GFR) at 6 months was unchanged compared with controls. Importantly, diastolic (DBP) and systolic BP (SBP) were significantly higher in Nedd4-2 ${ }^{K s p 1.3}$ mice and blood aldosterone levels were reduced (Figure 6). Aldosterone has a central role in $\mathrm{Na}^{+}$ conservation in the body and is regulated by the blood serum levels of $\mathrm{K}^{+}$and inversely by the levels of $\mathrm{Na}^{+}$. Low aldosterone levels therefore indicate increased $\mathrm{Na}^{+}$/reduced $\mathrm{K}^{+}$retention in Nedd4-2 $2^{K s p 1.3}$ mice even on a normal laboratory diet. Taken together, these results demonstrate the critical role of NEDD4- 2 in regulating $\mathrm{Na}^{+}$and $\mathrm{K}^{+}$levels in the blood.

Kidney damage is reduced by inhibition of ENaC. To determine if ENaC and NCC could give rise to the kidney damage, we treated mice with either amiloride (a specific inhibitor of $\mathrm{ENaC}$ ) or hydrochlorothiazide (HCTZ; to block NCC) from P20 (weaning) until P41 (Figure 7a). Blood aldosterone was significantly increased upon treatment with amiloride in both controls and Nedd4-2 $2^{K s p 1.3}$ mice (Figure $7 \mathrm{~b}$ ), correlating with the expected effects of amiloride 
a

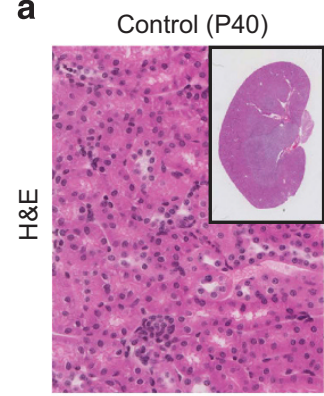

b

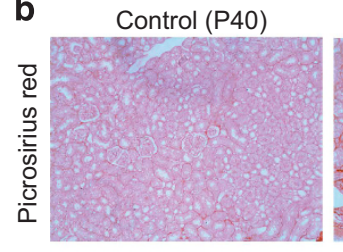

c
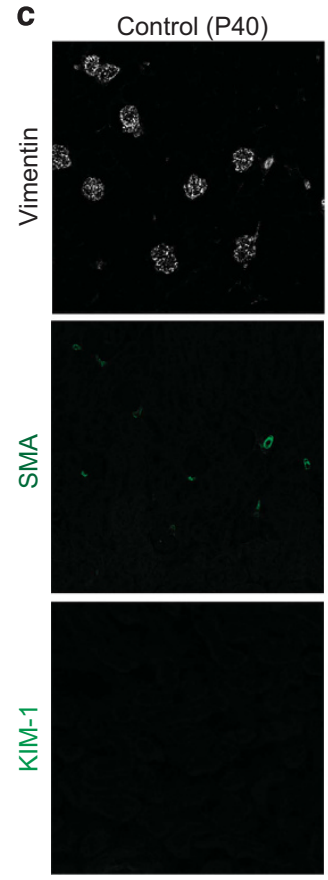

Nedd4-2 $2^{\text {Ksp1.3 }}$ (P40)

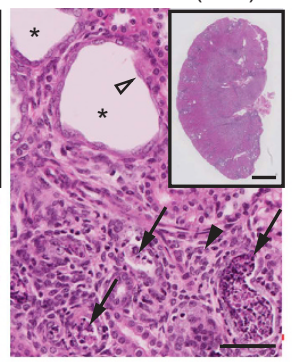

Nedd4-2 ${ }^{K s p 1.3}$ (P40)

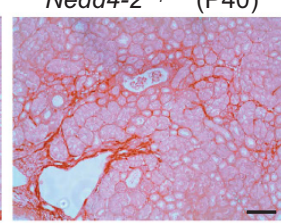

Nedd4-2 ${ }^{\text {Ksp1.3 }}$ (P40)
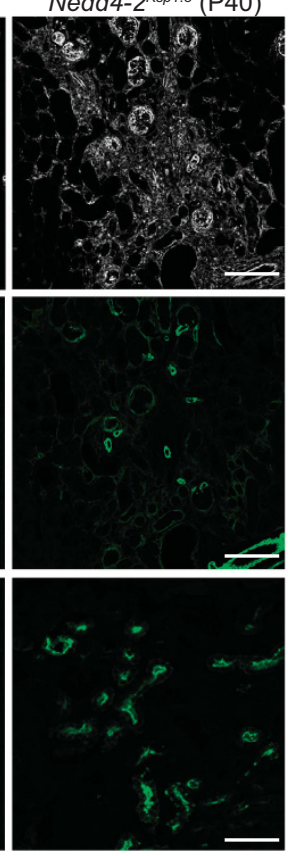

d

Control

Nedd4-2 ${ }^{\text {Ksp } 1.3}$
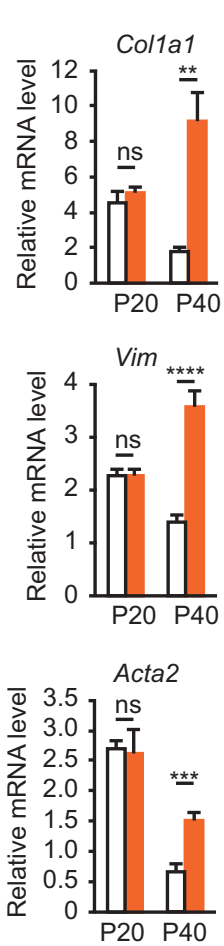

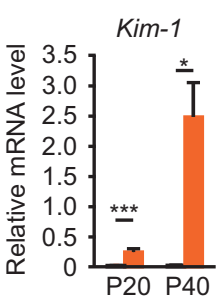

e
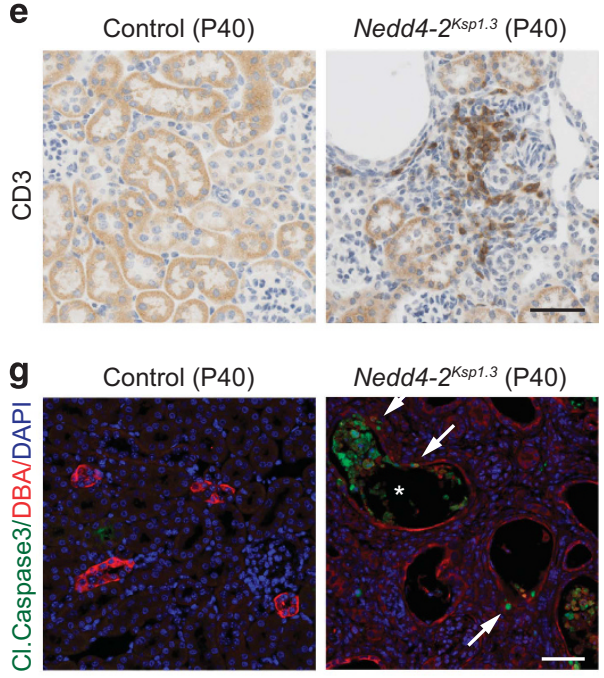

Nedd4-2 ${ }^{\text {Ksp1.3 }}(\mathrm{P} 40)$
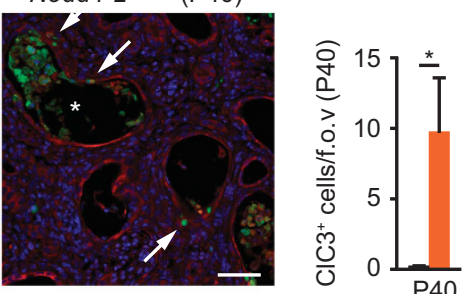

Figure 4 Progressive kidney injury in kidney-specific Nedd4-2KO mice. (a) Representative hematoxylin-eosin (H\&E) images show enlarged tubules (black asterisk), thinning of lining epithelium (open arrowhead), cellular debris within tubules (black arrows) and mesenchyme infiltration (black arrowhead) in P40 Nedd4-2 ${ }^{\text {Ksp1.3 }}$ mice. (b) Picrosirius red staining demonstrates fibrosis in Nedd4-2 ${ }^{K s p 1.3}$ kidneys (red). (c) Immunostaining shows increased expression of vimentin, SMA and Kim-1. (d) Increased gene expression for markers of kidney injury at P40, including collagen (encoded by Col1a1), vimentin (Vim), SMA (Acta2) and Kim-1, determined by qRT-PCR. Only Kim-1 levels were significantly altered at P20. Data are normalized to tbp levels and represent mean \pm s.e.m. for four mice per genotype. (e) Immune cell infiltration demonstrated by staining for CD3 (T-lymphocyte marker; and quantitated in (f)). ( $\mathbf{g}$ and $\mathbf{h}$ ) Immunostaining and quantitation of cleaved caspase-3-expressing cells shows apoptotic cells within tubules (white asterisk) and lining epithelia (white arrows) of Nedd4-2 ${ }^{K s p 1.3}$ kidneys at $P 40$. (f and $\left.\mathbf{h}\right) n=4$ per genotype. ${ }^{*} P<0.05,{ }^{* *} P<0.01$, ${ }^{* * \star} P<0.005$ and ${ }^{* * * *} P<0.001$. Scale bars: (a) $=50 \mu \mathrm{m}$, inset $=1 \mathrm{~mm} ;(\mathbf{b})=100 \mu \mathrm{m} ;$ (c) vimentin and SMA $=100 \mu \mathrm{m}, \mathrm{Kim}-1=50 \mu \mathrm{m} ;(\mathbf{e}$ and $\mathbf{g})=50 \mu \mathrm{m}$. fov, Field of view; NS $=$ not significant $(P>0.05)$

to block ENaC-mediated $\mathrm{Na}^{+}$reabsorption. In untreated Nedd4-2 ${ }^{K s p 1.3}$ kidneys, there was a significant increase in expression levels of $\mathrm{Vim}$ and Kim-1 when compared with untreated controls, as detected by qRT-PCR (Figures 7c and d). Importantly, in Nedd4-2 $2^{K s p 1.3}$ P40 kidneys amiloride treatment reduced the expression of both Vim and Kim-1. These data suggest that inhibiting $\mathrm{ENaC}$ activity with amiloride was able to alleviate the disease phenotype. On the contrary, HCTZ treatment had little beneficial effect in alleviating the kidney pathology. These results were supported by immunostaining for KIM-1 (Figures 7e and f). Taken together, these data demonstrate for the first time that a lack of NEDD4-2 increases $\mathrm{Na}^{+}$reabsorption through increased expression and activity of $\mathrm{ENaC}$, and that this results in kidney damage as well as hypertension on a standard laboratory diet. 


\section{Discussion}

In this study, we have identified a novel link between Nedd4-2 deficiency and nephropathy. We report for the first time that deletion of Nedd4-2 in the kidney results in a progressive kidney pathology characterized by renal fibrosis, cortical cysts, inflammation and tubular epithelial cell apoptosis. We have shown that this pathology critically involves a
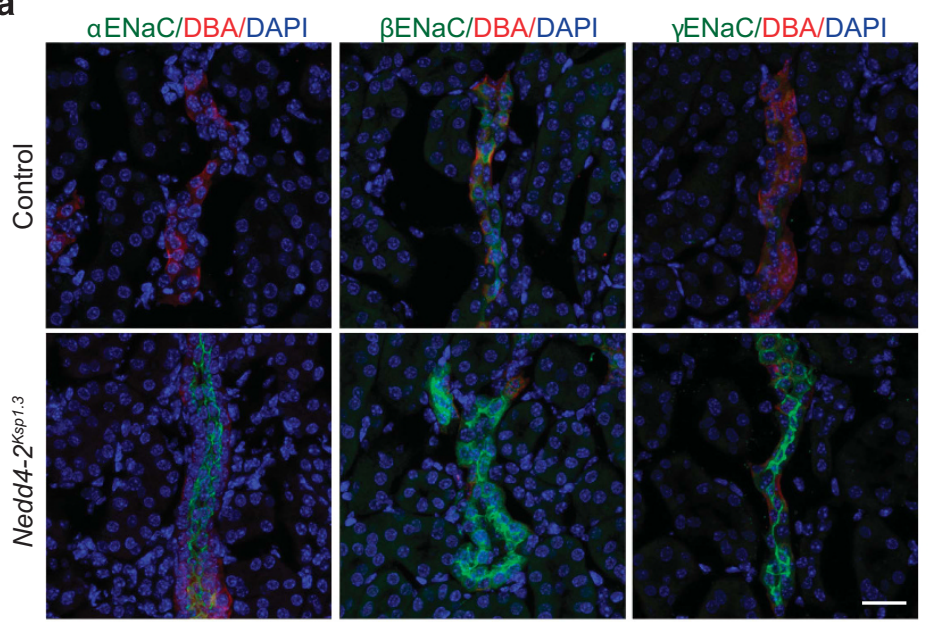

b

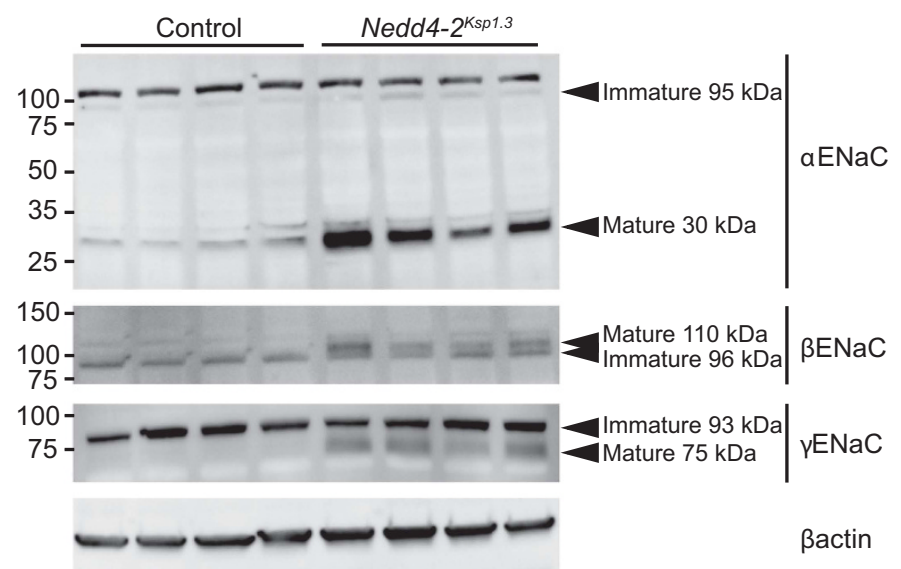

C

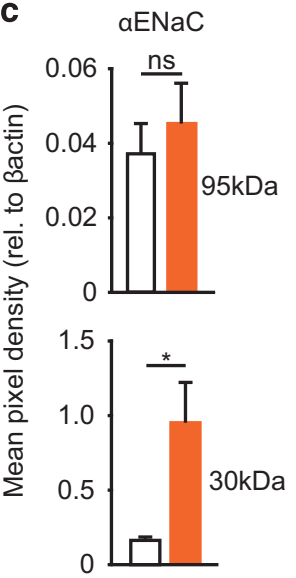

$\beta \mathrm{ENaC}$
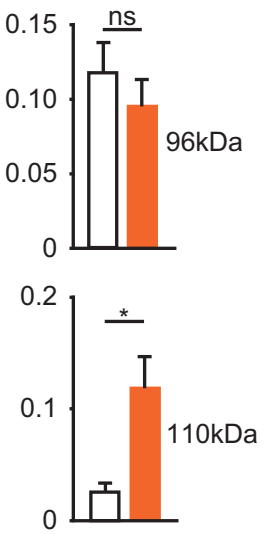

$\gamma \mathrm{ENaC}$

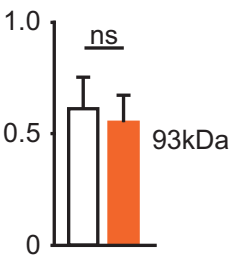

Bactin

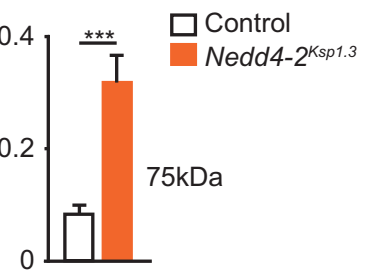

e
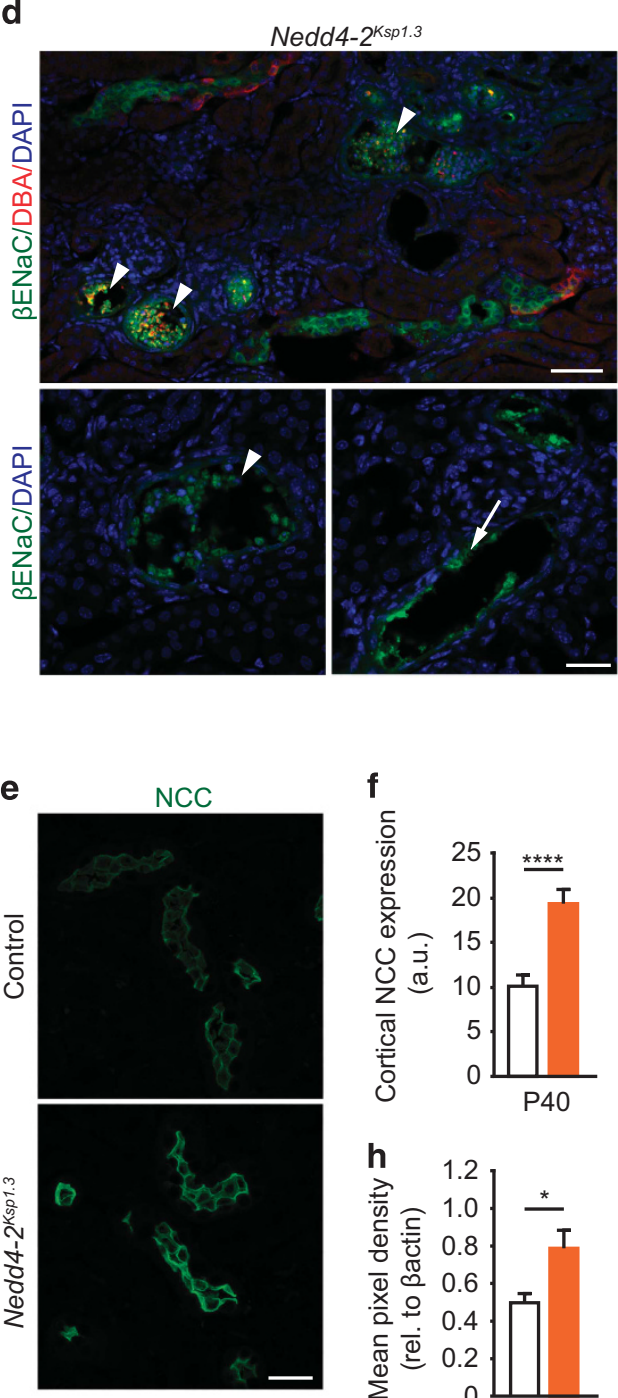

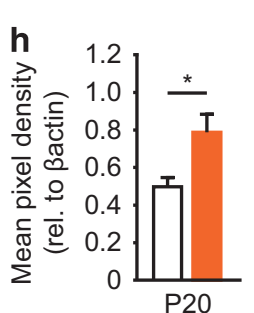

g

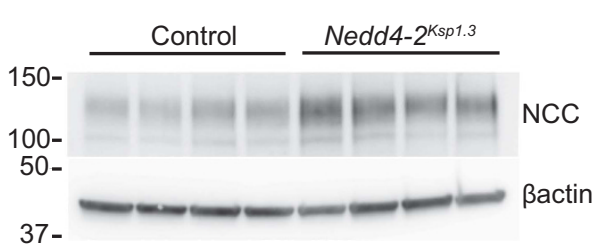

Figure 5 Increased expression of active ENaC and NCC in P40 Nedd4-2 ${ }^{K s p 1.3}$ mice. (a) Representative images showing increased $\alpha, \beta$ and $\gamma \mathrm{ENaC}$ subunits in Nedd4$2^{K \text { sp 1.3 }}$ kidneys also demonstrated by western blot (b) and quantified in (c). Note that only the mature forms of each subunit (cleaved and/or post-translationally modified) are upregulated in Nedd4-2 $2^{K s p 1.3}$ mice. (d) Representative images show $\beta \mathrm{ENaC}$ (green) localized to the damaged epithelium (arrows) and cellular debris inside tubules (arrowheads) in Nedd4-2 $2^{K s p 1.31}$ kidneys. (e-h) NCC is upregulated in Nedd4- $2^{K s p 1.3}$ kidneys as shown by immunohistochemistry in (e), quantitated in (f), and by immunoblot analysis ( $\mathbf{g}$ and $\mathbf{h}$ ). Data are presented as mean \pm s.e.m. (f) $n=3$ per genotype. ${ }^{*} P<0.05,{ }^{* *} P<0.01$ and ${ }^{* *} P<0.005$. Scale bars: (a and e) $=25 \mu \mathrm{m}$ (P40), (d) (top) $=25 \mu \mathrm{m}$, (bottom) $=12.5 \mu \mathrm{m}(\mathrm{P} 40)$ 
Table 1 Urine and plasma electrolytes in control and tubule-specific Nedd4-2 ${ }^{K s p 1.3}$ mice at 6 months

\begin{tabular}{|c|c|c|c|c|c|}
\hline \multirow[b]{2}{*}{ Body weight (g) } & \multicolumn{2}{|l|}{ Control } & \multicolumn{2}{|c|}{ Nedd4-2 $2^{K s p 1.3}$} & \multirow{2}{*}{$\begin{array}{r}\boldsymbol{P} \text {-value } \\
0.025\end{array}$} \\
\hline & $33.838 \pm 1.0192$ & {$[5]$} & $27.22 \pm 0.6788$ & {$[7]^{*}$} & \\
\hline \multicolumn{6}{|l|}{ Intake } \\
\hline Food (g/g BW/24h) & $0.085 \pm 0.007$ & [5] & $0.182 \pm 0.016$ & {$[7]^{*}$} & 0.013 \\
\hline Water (ml/g BW/24r) & $0.164 \pm 0.034$ & [5] & $0.427 \pm 0.113$ & {$[7]^{*}$} & 0.018 \\
\hline \multicolumn{6}{|l|}{ Output } \\
\hline Feces (g/g BW/24 h) & $0.023 \pm 0.003$ & [5] & $0.059 \pm 0.008$ & {$[7]^{*}$} & 0.025 \\
\hline Urine $(\mathrm{ml} / \mathrm{g} \mathrm{BW} / 24 \mathrm{~h})$ & $0.033 \pm 0.005$ & [5] & $0.241 \pm 0.083$ & {$[7]^{*}$} & 0.025 \\
\hline $\mathrm{Na}^{+}$excretion $(\mu \mathrm{mol} / 24 \mathrm{~h})$ & $124.824 \pm 22.630$ & [5] & $125.156 \pm 26.725$ & [7] & 0.631 \\
\hline $\mathrm{Na}^{+} / \mathrm{Cr}\left(10^{3}\right)$ & $29.740 \pm 2.517$ & [5] & $29.664 \pm 3.750$ & [7] & 0.631 \\
\hline $\mathrm{K}^{+}$excretion $(\mu \mathrm{mol} / 24 \mathrm{~h})$ & $239.096 \pm 28.534$ & [5] & $359.383 \pm 48.426$ & {$[7]$} & 0.070 \\
\hline $\mathrm{K}^{+} / \mathrm{Cr}\left(10^{3}\right)$ & $59.050 \pm 5.659$ & [5] & $87.204 \pm 6.161$ & {$[7]^{*}$} & 0.010 \\
\hline $\mathrm{Na}^{+} / \mathrm{K}^{+}$ & $0.522 \pm 0.063$ & [5] & $0.339 \pm 0.015$ & {$[7]^{*}$} & 0.030 \\
\hline $\mathrm{Ca}^{2^{+}}$excretion $(\mu \mathrm{mol} / 24 \mathrm{~h})$ & $2.51635 \pm 0.5$ & [3] & $15.8835 \pm 1.9629$ & {$[7]^{*}$} & 0.017 \\
\hline $\mathrm{Ca}^{2^{+}} / \mathrm{Cr}\left(10^{3}\right)$ & $0.61869 \pm 0.0063$ & [3] & $4.627573 \pm 1.2878$ & {$[7]^{*}$} & 0.017 \\
\hline Urea excretion ( $\mu \mathrm{mol} / 24 \mathrm{~h})$ & $1212.949 \pm 169.696$ & [5] & $1608.448 \pm 202.021$ & {$[7]$} & 0.260 \\
\hline Urea/Cr $\left(10^{3}\right)$ & $295.483 \pm 26.187$ & [5] & $389.929 \pm 22.714$ & {$[7]^{*}$} & 0.048 \\
\hline Protein excretion ( $\mu \mathrm{g} / 24 \mathrm{~h})$ & $3200.755 \pm 666.685$ & [5] & $2421.292 \pm 388.522$ & [7] & 0.429 \\
\hline Protein $/ \mathrm{Cr}\left(10^{3}\right)$ & $825.425 \pm 157.029$ & [5] & $608.037 \pm 94.994$ & [7] & 0.268 \\
\hline GFR (ml/g BW/24 h) & $7.055 \pm 1.108$ & [5] & $7.371 \pm 0.888$ & {$[7]$} & 0.710 \\
\hline \multicolumn{6}{|l|}{ Plasma } \\
\hline $\mathrm{Na}^{+}(\mathrm{mM})$ & $147.600 \pm 0.454$ & [24] & $152.600 \pm 0.832$ & {$[16]^{\star \star \star}$} & $<0.0001$ \\
\hline $\mathrm{K}^{+}(\mathrm{mM})$ & $3.736 \pm 0.097$ & [24] & $2.731 \pm 0.131$ & {$[16]^{\star \star \star}$} & $<0.0001$ \\
\hline
\end{tabular}

Values are given as average \pm s.e.m. Number of mice are indicated in square brackets. $P$-values were determined using a Mann-Whitney test for non-normally distributed data. ${ }^{*} P<0.05,{ }^{* \star \star} P<0.005$. Number of animals analyzed are shown within parentheses $[n]$
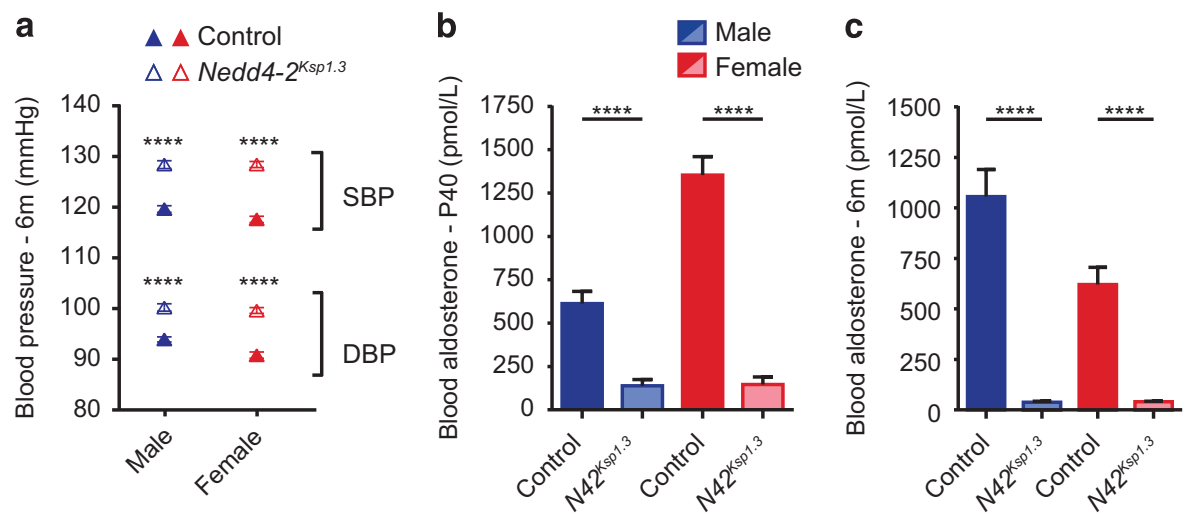

Figure 6 Nedd4- $2^{K s p 1.3}$ mice have increased BP. (a) SBP and DBP of 6-month-old control and Nedd4-2 ${ }^{K s p 1.3}$ mice. (b and c) Blood serum aldosterone levels were significantly reduced in the Nedd4-2Ksp1.3 mice as compared with the control mice at the age of P40 (b) and 6 months (c). All mice were fed a standard laboratory diet. BP was recorded from six to seven mice per genotype (control and Nedd4-2 ${ }^{K s p 1.3}$ ) and gender. ${ }^{\star \star \star \star} P<0.001$

regulation of salt uptake via $\mathrm{ENaC}$, even on a standard laboratory diet.

Absence of Nedd4-2 results in kidney damage. As described previously, most Nedd4-2-1- mice die perinatally from respiratory distress. ${ }^{5}$ However, the few Nedd4-2-/mice that survive display progressive kidney damage developing shortly after birth, with pathological features similar to those commonly observed in patients with nephropathies, such as fibrosis, cortical cysts, enlarged tubules and cellular casts. ${ }^{17}$ Given the early postnatal lethality of Nedd4- $2^{-/}$mice, we generated a renal-tubule-specific line $\left(\right.$ Nedd4-2 ${ }^{K s p 1.3}$ ) to investigate the cause of this kidney damage. Nedd4-2 ${ }^{K s p 1.3}$ mice display a progressive renal pathology similar to the global Nedd4-2 $2^{-1-}$ mice, characterized by significant tubular epithelial cell apoptosis and fibrosis. By 6 months of age, Nedd4-2 $2^{K s p 1.3}$ mice develop prominent phenotypes of chronic kidney disease (CKD), including hydronephrosis, polyuria and polydipsia. Nedd4$2^{K s p 1.3}$ mice display increased serum $\mathrm{Na}^{+}$levels and increased $\mathrm{K}^{+}$excretion, as well as high $\mathrm{BP}$ and low aldosterone, which are all indicative of increased $\mathrm{Na}^{+}$ retention. Somewhat surprisingly Nedd4-2 $2^{K s p 1.3}$ mice maintained normal GFR at 6 months old, which is most likely due to remaining Nedd4-2 expression in the glomerulus and the progressive nature of the disease. 
a

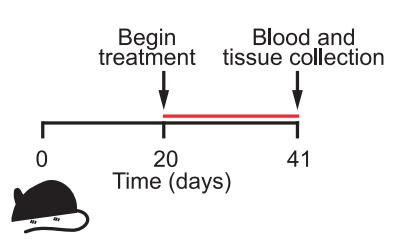

b

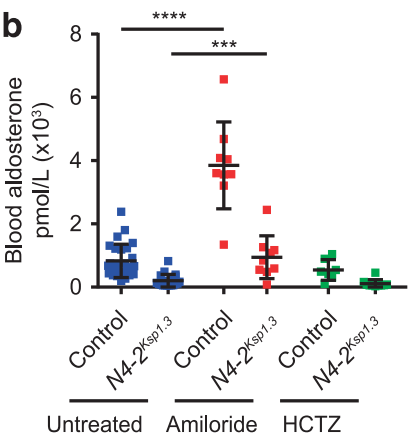

e

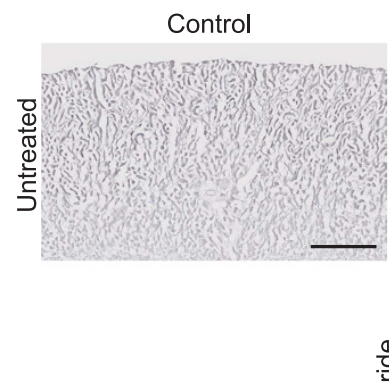

C

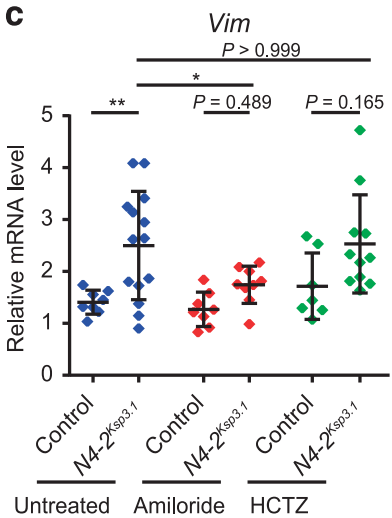

d

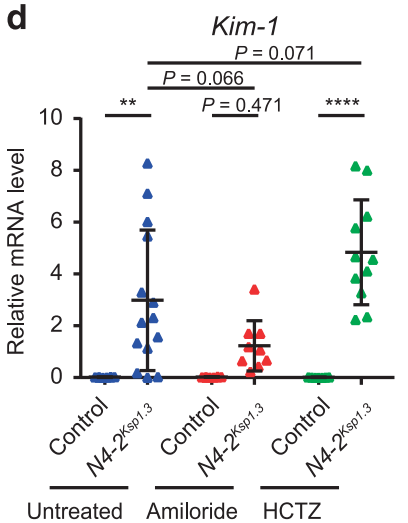

f

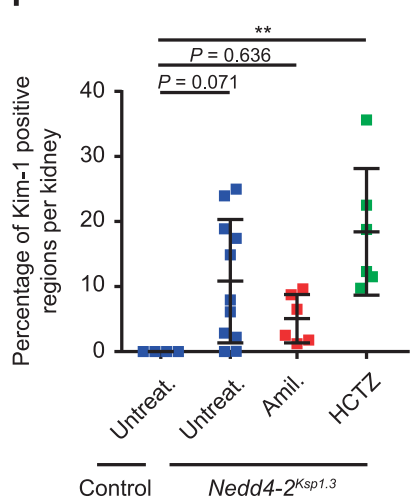

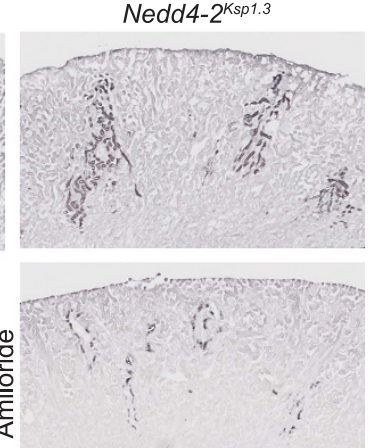

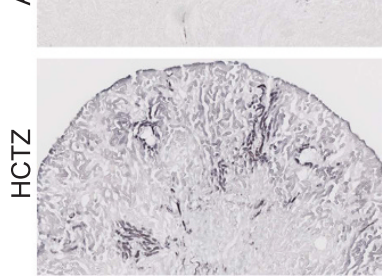

Figure 7 Treatment of Nedd4-2 $2^{K s p 1.3}$ mice with diuretic drugs to block ENaC and NCC variably affects kidney damage. (a) Time course of treatment from P20 until P40. Drugs were added to the drinking water daily: amiloride $(2 \mathrm{mg} / \mathrm{kg})$ and HCTZ (10 mg/kg). (b) Blood aldosterone levels are shown for all treatment groups at P40. Amiloride treatment increases levels of aldosterone, as expected. (c) qRT-PCR data showing Vimentin and Kim-1 expression levels in control and Nedd4-2 ${ }^{\text {Ksp } 1.3}$ kidneys, administered with diuretic drugs in the tap water. (e and f) Representative images of Kim-1 immunostaining showing areas of kidney damage in the cortex in untreated and treated mice (e), and the result of quantitation (f). (b-d) $n=9-14$. (f) Samples were randomly selected from drug treatment experiment; $n=4-6$ for contro untreated and Nedd4-2 ${ }^{K s p 1.3}$ amiloride and HCTZ treated, $n=11$ for Nedd4-2 ${ }^{K s p 1.3}$ untreated (one dot represents one mouse). ${ }^{*} P<0.05$, ${ }^{* \star} P<0.01,{ }^{* \star \star} P<0.005$ and ${ }^{* * \star *} P<0.001$. Data are presented as mean \pm s.d. One-way analysis of variance (ANOVA) with Bonferroni's post-test for comparison between multiple groups was used. Scale bar: $(\mathbf{c})=500 \mu \mathrm{m}$

Hypertension is known to contribute to kidney damage and CKD. ${ }^{18}$ In both Nedd4-2-/- and Nedd4-2 $2^{K s p 1.3}$ mice, kidney damage begins soon after birth indicating that this pathology is unlikely to be a secondary effect of hypertension. Furthermore, additional models of Nedd4-2 deletion, which exhibit a similar degree of hypertension, display no evidence of kidney damage..$^{7,8}$ These data suggest that the kidney pathology observed in Nedd4-2 KO mice is due to a primary effect on the tubular epithelia rather than as a result of hypertension.

Kidney pathology caused by increased ENaC expression. Importantly, our Nedd4-2 KO mice develop kidney damage on a standard laboratory diet, and the increased $\mathrm{Na}^{+}$reabsorption appears to be due, at least in part, to increased levels of ENaC on the plasma membrane. Indeed, we observed greater expression of the active forms of all three ENaC subunits in the collecting ducts of Nedd4-2 ${ }^{K s p 1.3}$ kidneys. In addition, we also observed a significant increase in levels of NCC, which was noted in the Nedd4L Pax8/LC1 model. ${ }^{8}$ The discrepancy in ENaC expression levels between different Nedd4-2 mutant mouse models can be explained by some expression of functional Nedd4-2 splice variants in other Nedd4-2 mutant mouse lines. ${ }^{5}$ In our Nedd4-2 ${ }^{K s p 1.3}$ mice, no functional NEDD4-2 can be expressed given that the HECT domain is targeted.

The significance of increased levels of active $\mathrm{ENaC}$ in the development of kidney disease in Nedd4-2 $2^{K s p 1.3}$ mice is clear from our data showing that amiloride treatment reduces renal damage. Thus, increased functional $\mathrm{ENaC}$ at the plasma membrane appears to be a contributing factor to the development of kidney disease. Indeed, ENaC has been implicated in the development of kidney damage in Dahl salt-sensitive rats that develop hypertension and renal damage after 4 weeks on a high-salt diet. ${ }^{19,20}$

In our Nedd4-2 $2^{K s p 1.3}$ mice, inhibition of NCC alone (with HCTZ) was not able to rescue the disease phenotype in our Nedd4-2 $2^{K s p 1.3}$ mice, suggesting that ENaC, and not NCC, is a major contributor to the disease. Administration of amiloride, however, did not fully rescue the kidney damage seen in Nedd4-2 ${ }^{K s p 1.3}$ mice. We therefore hypothesize that in addition to increased $\mathrm{Na}^{+}$absorption by $\mathrm{ENaC}$, other NEDD4-2regulated mechanisms may contribute to the renal pathology seen in Nedd4-2-deficient animals.

Clinical significance of NEDD4-2 in salt induced kidney damage. The effect of Nedd4-2 deficiency in renal pathology has not been previously characterized. There is 
evidence that Nedd4-2 contributes to salt-sensitive hypertension in humans, as multiple single-nucleotide polymorphisms (SNPs) in this gene have been linked to increased ENaC expression and hypertension. ${ }^{21-25}$ However, their possible role in kidney disease has not been reported. In a previous study assessing NEDD4L variants in hypertension, two patients with a nonsynonymous variant of $N E D D 4 L$ were also found to have end-stage renal disease (ESRD). ${ }^{26}$ Thus, SNPs of NEDD4L can lead to hypertension, as well as contribute to renal diseases in patients, similar to that observed in the Nedd4-2 $2^{-/-}$and Nedd4-2 $2^{K s p 1.3}$ mice.

\section{Conclusions}

Approximately 1 in 10 people worldwide suffer from varying degrees of CKD, and those with hypertension or diabetes are at even higher risk. ${ }^{27}$ In addition, CKD can itself contribute to hypertension and cardiovascular disease further fueling the burden of CKD on healthcare systems worldwide. ${ }^{28}$ Acute kidney injury can initiate the onset of chronic and ESRD ${ }^{29,30}$ and is therefore an important focus for early intervention to limit kidney pathology. NEDD4-2 is a critical regulator of $\mathrm{Na}^{+}$ion channels along the nephron, and polymorphisms in the human NEDD4L gene are associated with salt-sensitive hypertension and kidney disease. This makes NEDD4-2, and proteins that may regulate it, important targets for the development of therapeutics for improved health care of patients with kidney disease. The studies reported here provide new data toward the understanding of the function of NEDD4-2, its critical role in $\mathrm{Na}^{+}$homeostasis, and the contribution of increased $\mathrm{Na}^{+}$reabsorption to renal disease.

\begin{abstract}
Materials and Methods
Mouse lines. Global Nedd4-2 $2^{-1}$ mice were generated in our laboratory previously. ${ }^{5}$ Kidney-specific inactivation of Nedd4-2 was achieved by crossing the Nedd4-2-floxed line $\left(\text { Nedd4- } 2^{\text {fl/fl }}\right)^{10}$ with the Ksp-Cre transgenic strain from Peter Igarashi's laboratory (obtained through Christina Mitchell). ${ }^{12}$ Homozygous Nedd4-2floxed mice (Nedd4-2 $\left.2^{\text {flfl|l|}}\right)$ were crossed with heterozygous mice expressing the Ksp1.3-Cre transgene. From the filial (F) 1 progeny, litters with heterozygous deletion of Nedd4-2 gene that harbored the Ksp1.3-Cre transgene (Ksp1.3-Cre; Nedd4 $-2^{i \mid /+}$ ) were selected and further crossed with Nedd4-2 $2^{\mathrm{i} / \mathrm{fl}}$ mice to obtain mice expressing complete deletion of Nedd4-2 in the F2 progeny (Ksp1.3-Cre;

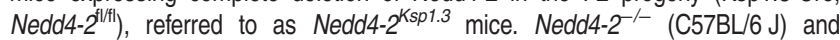
Nedd4-2 $2^{K s p 1.3}$ (C57BL/6 J) mice were bred at the SA Pathology Animal Facility (Adelaide, Australia) under specific pathogen-free conditions. All animal studies were approved by the institutional animal ethics and biosafety committees at SA Pathology, and were carried out according to the National Health and Medical Research Council guidelines.

For tissue collection, mice were anesthetized and blood collected by cardiac puncture. Animals were then quickly killed by cervical dislocation. Kidneys were removed and the fibrous capsule dissected off. One kidney was snap frozen in liquid nitrogen, and the other was cut in half in the coronal plane and immersion fixed in Histochoice (ProSciTech, Kirwan, QLD, Australia) for $48 \mathrm{~h}$ at $4{ }^{\circ} \mathrm{C}$. One-half of the kidney was paraffin embedded and the other half was embedded in OCT for frozen sections.
\end{abstract}

Drug treatment studies. For drug treatment studies, mice were treated with amiloride (Sigma-Aldrich, St. Louis, MO, USA; $2 \mathrm{mg} / \mathrm{kg}$ per day: $14 \mathrm{mg} / \mathrm{l}^{31}$ or HCTZ (Sigma-Aldrich; $10 \mathrm{mg} / \mathrm{kg}$ per day: $67 \mathrm{mg} / \mathrm{l}^{32}$ in the drinking water. Treatment began after weaning at $\mathrm{P} 20$, with water changed daily for 21 days. Animals were anesthetized for blood and tissue collection as above. During treatment, mice were group housed in standard conditions with free access to food and water and monitored daily.
Metabolic cage studies. Male, 6-month-old Nedd4-2 ${ }^{K s p 1.3}$ and control littermates were housed in metabolic cages for $24 \mathrm{~h}$ following three training sessions of $6 \mathrm{~h}$ each. Mice were provided ad libitum access to deionized drinking water and standard pelleted chow, and urine was collected every $5 \mathrm{~h}$. At the end of the experiment, blood and tissue samples were taken as described above.

Histological analysis. Kidney tissues fixed in histochoice were embedded in paraffin and $5-\mu \mathrm{m}$ sections were cut using a paraffin microtome. The sections were mounted on glass slides, deparaffinized with xylene, dehydrated through graded series of ethanol and stained with hematoxylin-eosin. To evaluate collagen deposition using picrosirius red, slides were stained for $1 \mathrm{~h}$ in saturated picric acid with $0.1 \%$ Direct Red 80 (Sigma-Aldrich), and then washed in $0.01 \mathrm{~N}$ hydrochloric acid for $2 \mathrm{~min}$. Digital images were acquired by using a NanoZoomer Imager (Hamamatsu Photonics K. K., Japan).

Antibodies and immunohistochemistry. Paraffin sections $(5 \mu \mathrm{m})$ were deparaffinized and hydrated in a graded ethanol series. Heat-mediated antigen retrieval was carried out by boiling for $10 \mathrm{~min}$ in $10 \mathrm{mM}$ citric acid solution (pH 6). Tissue sections were blocked with $10 \%$ goat serum. Primary antibodies used were: rabbit anti- $\alpha \mathrm{ENaC}$ and rabbit anti- $\gamma \mathrm{ENaC} ;{ }^{33}$ rabbit anti- $\beta \mathrm{ENaC}{ }^{5}$ fluoresceinconjugated Lotus tetragonolobus agglutinin (cat. no. FL-1321; Vector Laboratories, Burlingame, CA, USA); rhodamine-labeled DBA (cat. no. RL-1032; Vector Laboratories); FITC-conjugated mouse anti-SMA (cat. no. F3777; Sigma-Aldrich); rabbit anti-vimentin (cat. no. ab92547; Abcam, Cambridge, UK); rabbit anti-NCC (cat. no. ab3553; Abcam); rabbit anti-cleaved caspase-3 (cat. no. 9661 S; Cell signaling Technologies, Danvers, MA, USA); rat anti-Kim-1 (cat. no. MAB1817; R\&D Systems, Minneapolis, MN, USA). Immunostainings for Kim-1 and all ENaC subunits were carried out on frozen sections $(14 \mu \mathrm{m})$. For colorimetric staining, endogenous peroxidase was blocked by incubation in $3 \%$ hydrogen peroxide before primary antibody addition, sections were incubated with the corresponding biotinylated secondary antibodies and sequentially incubated in ABC-Peroxidase Solution according to the manufacturer's protocol (Thermo Fisher Scientific, Waltham, MA, USA), before being developed with 3,3'-diaminobenzidine (DAB; Sigma-Aldrich). Sections were lightly counterstained with hematoxylin, and then dehydrated and mounted. For fluorescence staining, tissue sections were incubated with the corresponding fluorescently tagged secondary antibodies (AlexaFluor-488 or -568; Thermo Fisher Scientific), counterstained with DAPI and mounted in Prolong Gold Antifade reagent (Thermo Fisher Scientific). Stained samples were imaged using an LSM 700 confocal microscope using Zen 2011 (Black Edition) version 8.1.5.484 (Carl Zeiss Microscopy, Jena, Germany) or Nanozoomer Imager (Hamamatsu Photonics K. K., Japan). Image analysis was carried out using ImageJ (NIH, Bethesda, MD, USA), Photoshop and Adobe Image Suite (Adobe, San Jose, CA, USA) Software.

Quantification. Cleaved caspase-3-positive or CD3-positive cells were counted in eight random cortical fields from four kidneys of each genotype at x20 magnification. Quantitation of total fluorescence from NCC-positive cells was carried out from 4-6 random fields in the cortex of three mice each for control and Nedd4$2^{K s p 1.3}$ kidneys at $\times 100$ magnification. Total fluorescence levels for each image was measured using ImageJ $(\mathrm{NIH})$. Percentage area of Kim-1-positive staining was measured in the cortex and medulla of drug-treated and -untreated mice. Frozen sections $(14 \mu \mathrm{m})$ from at least six mice per group were immunostained for Kim-1 and then developed using DAB. Each section was then imaged on the Nanozoomer Imager and the percentage area of Kim-1 staining in the cortex and medulla was quantitated using ImageJ (NIH).

Immunoblotting. Kidneys were lysed in ice-cold extraction buffer at $\mathrm{pH} 7.5$ (50 mM Tris- $\mathrm{HCl}$, pH 7.5, $1 \mathrm{mM}$ EDTA, $1 \mathrm{mM}$ EGTA, $0.27 \mathrm{M}$ sucrose, $0.1 \%$ $\beta$-mercaptoethanol and HALT protease and phosphatase inhibitor cocktail; Thermo Fisher Scientific). Tissue was homogenized, frozen in liquid nitrogen, immediately thawed and incubated at $4{ }^{\circ} \mathrm{C}$ on a nutator for $30 \mathrm{~min}$ and centrifuged at 13000 r.p. $\mathrm{m}$. for $5 \mathrm{~min}$. Supernatant protein $(100 \mu \mathrm{g})$ was combined with protein load buffer (100 mM Tris-HCl, pH 6.8, 200 mM DTT, 4\% SDS, 0.2\% bromophenol blue, 20\% glycerol), heated at $95^{\circ} \mathrm{C}$ for $5 \mathrm{~min}$, loaded onto $4-20 \%$ precast SDS-PAGE gels (Bio-Rad, Hercules, CA, USA) and transferred to PVDF membrane using the Transblot Turbo Instrument (Bio-Rad). Membranes were blocked with $1 \%$ skim milk in TBS-T (Tris-buffered saline/0.05\% Tween-20) and primary antibodies were added: rabbit anti-Nedd4-2, ${ }^{34}$ mouse anti- $\beta$-actin (clone AC15; Sigma-Aldrich), or ENaC and NCC antibodies described above. HRP secondary antibodies were added 
(Merck Millipore, Billerica, MA, USA) and developed with a ECL Prime substrate (GE Healthcare, Paramatta, NSW, Australia) on a ChemiDoc Touch Imager (Bio$\mathrm{Rad})$.

Real-time quantitative PCR. Total RNA was isolated from kidneys using TRIzol Reagent (Thermo Fisher Scientific) and RNA was reverse-transcribed with a High Capacity cDNA Reverse Transcription Kit (Applied Biosciences, Foster city, CA, USA). QRT-PCR was performed and analyzed as described, ${ }^{35}$ where all data are normalized to tbp (TATA box-binding protein) levels. Primer sequences are detailed in Supplementary Table 1.

BP measurements. BP was measured by a tail cuff system (CODA Monitor; Kent Scientific Corporation, Torrington, CT, USA) as described previously. ${ }^{36}$ Briefly, 6-month-old mice were placed into a plastic tube restrainer, BP recording cuffs were placed over the tail and the mice were allowed to adapt to the restrainer for $5 \mathrm{~min}$. BP was then measured for 10 acclimation cycles followed by 25-30 measurement cycles. Heating pads were used to keep the mice warm throughout the experiment to ensure sufficient blood flow to the tail. Blood pressure was recorded from six to seven mice per genotype (control and Nedd4-2ksp1.3 ) and gender.

Electrolytes and aldosterone. Electrolytes and aldosterone levels in blood and urine were carried out by SA Pathology. Urinary and plasma $\mathrm{Na}^{+}, \mathrm{K}^{+}, \mathrm{Cl}^{-}$and creatinine were measured using an Advia 2400 Chemistry System (Siemens, Bayswater, VIC, Australia), and urine osmolality was measured with an Advanced 3320 Osmometer (Advanced Instruments, Thermo Fisher Scientific, Waltham, MA, USA). Plasma aldosterone levels were measured using a Liaison Aldosterone Kit and a Chemiluminescent Analyzer (Diasorin, Saluggia, Italy). GFR was estimated based on creatinine clearance using a standard formula: GFR = urine flow $\times$ [urine creatinine]/[plasma creatinine]. ${ }^{37}$

Statistical analysis of data. Statistical analysis was performed using GraphPad Prism software, version 6.0 (San Diego, CA, USA). One-way ANOVA with Bonferroni's post-test was used to assess rescue of kidney injury by qRT-PCR after treatment with diuretics in control and Nedd4-2 ${ }^{K s p 1.3}$ mice. Metabolic cage data and cleaved caspase-3 quantitation was assessed using a Mann-Whitney test for nonnormally distributed data. Remaining data were analyzed using unpaired two-tailed Student's $t$-test with Welch's correction, Nedd4-2 ${ }^{K \text { sp1.3 }}$ versus controls. A P-value of $\leq 0.05$ was considered significant. All values are presented as mean \pm s.e.m. unless otherwise stated.

Study approval. All experimental procedures were approved by the SA Pathology/CALHN animal ethics committee and carried out in accordance with the local animal welfare act.

\section{Conflict of Interest}

The authors declare no conflict of interest.

Acknowledgements. We are grateful to John Finnie for helping with the pathological analysis of kidneys, lan Smyth and Darren Saunders for helpful discussions, Johannes Loffing for the gift of $\alpha$ and $\gamma \mathrm{ENaC}$ antibodies, and Christina Mitchell for supplying the Ksp1.3-Cre mice following permission from Peter Igarashi. We also acknowledge the help of SA pathology animal house staff. This work was supported by a National Health and Medical Research Council (NHMRC) of Australia Senior Principal Research Fellowship (GNT1103006) and project grants (GNT1020755 and GNT1099307) to SK, and a Mary Overton Early Career Fellowship to JAM.

\section{Author contributions}

$\mathrm{JM}, \mathrm{NAB}$ and SK conceptualized the project; JM made the initial observation of renal pathology in Nedd4-2 - / - animals; JM, OA, NAB and PG carried out early studies on characterization of the renal phenotype in Nedd4-2-/- animals; OA and NAB generated the Nedd4-2 $2^{K s p 1.3}$ mice and made initial observations on animal viability; $\mathrm{TH}$ and JM, with assistance from $\mathrm{OA}$, carried out detailed pathophysiological analysis of Nedd4-2 $2^{K s p 1.3}$ and Nedd4-2 $2^{--}$mice and performed the drug treatment experiments; TLH, JM, NAB, OA, PG and SK analyzed data; TLH, JAM and SK wrote the manuscript and HK provided the Nedd4-2 ${ }^{\text {lox }}$ mice. All authors commented on the manuscript.
1. Harvey KF, Dinudom A, Cook DI, Kumar S. The Nedd4-like protein KIAA0439 is a potential regulator of the epithelial sodium channel. J Biol Chem 2001; 276: 8597-8601.

2. Kamynina $E$, Debonneville $C$, Bens $M$, Vandewalle $A$, Staub $O$. A novel mouse Nedd4 protein suppresses the activity of the epithelial Na+ channel. FASEB J 2001; 15 204-214.

3. Fotia AB, Dinudom A, Shearwin KE, Koch JP, Korbmacher C, Cook DI et al. The role of individual Nedd4-2 (KIAA0439) WW domains in binding and regulating epithelial sodium channels. FASEB J 2003; 17: 70-72.

4. Arroyo JP, Lagnaz D, Ronzaud C, Vazquez N, Ko BS, Moddes L et al. Nedd4-2 modulates renal $\mathrm{Na}+\mathrm{Cl}-$ cotransporter via the aldosterone-SGK1-Nedd4-2 pathway. J Am Soc Nephrol 2011; 22: 1707-1719.

5. Boase NA, Rychkov GY, Townley SL, Dinudom A, Candi E, Voss AK et al. Respiratory distress and perinatal lethality in Nedd4-2-deficient mice. Nat Commun 2011; 2: 287.

6. Araki N, Umemura M, Miyagi Y, Yabana M, Miki Y, Tamura K et al. Expression, transcription, and possible antagonistic interaction of the human Nedd4L gene variant: implications for essential hypertension. Hypertension 2008: 51: 773-777.

7. Shi PP, Cao XR, Sweezer EM, Kinney TS, Williams NR, Husted RF et al. Salt-sensitive hypertension and cardiac hypertrophy in mice deficient in the ubiquitin ligase Nedd4-2. Am J Physiol Renal Physiol 2008; 295: F462-F470.

8. Ronzaud C, Loffing-Cueni D, Hausel P, Debonneville A, Malsure SR, Fowler-Jaeger $\mathrm{N}$ et al. Renal tubular NEDD4-2 deficiency causes NCC-mediated salt-dependent hypertension. $J$ Clin Invest 2013; 123: 657-665.

9. Al-Qusairi L, Basquin D, Roy A, Rajaram RD, Maillard MP, Subramanya AR et al. Renal tubular ubiquitin-protein ligase NEDD4-2 is required for renal adaptation during long-term potassium depletion. J Am Soc Nephrol 2017; 28: 2431-2442.

10. Kimura T, Kawabe H, Jiang C, Zhang W, Xiang YY, Lu C et al. Deletion of the ubiquitin ligase Nedd4L in lung epithelia causes cystic fibrosis-like disease. Proc Natl Acad Sci USA 2011; 108: 3216-3221.

11. Ichimura $\mathrm{T}$, Bonventre JV, Bailly V, Wei H, Hession CA, Cate RL et al. Kidney injury molecule-1 (KIM-1), a putative epithelial cell adhesion molecule containing a novel immunoglobulin domain, is up-regulated in renal cells after injury. J Biol Chem 1998; 273: 4135-4142.

12. Shao X, Somlo S, Igarashi P. Epithelial-specific Cre/lox recombination in the developing kidney and genitourinary tract. J Am Soc Nephrol 2002; 13: 1837-1846.

13. Grande MT, Sanchez-Laorden B, Lopez-Blau C, De Frutos CA, Boutet A, Arevalo M et al. Snail1-induced partial epithelial-to-mesenchymal transition drives renal fibrosis in mice and can be targeted to reverse established disease. Nat Med 2015; 21: 989-997.

14. Hughey RP, Mueller GM, Bruns JB, Kinlough CL, Poland PA, Harkleroad KL et al. Maturation of the epithelial $\mathrm{Na}+$ channel involves proteolytic processing of the alpha- and gammasubunits. J Biol Chem 2003; 278: 37073-37082.

15. Ergonul Z, Frindt G, Palmer LG. Regulation of maturation and processing of ENaC subunits in the rat kidney. Am J Physiol Renal Physiol 2006; 291: F683-F693.

16. Zhou R, Patel SV, Snyder PM. Nedd4-2 catalyzes ubiquitination and degradation of cell surface ENaC. J Biol Chem 2007; 282: 20207-20212.

17. Wolf MT. Nephronophthisis and related syndromes. Curr Opin Pediatr 2015; 27: 201-211.

18. Gargiulo R, Suhail F, Lerma EV. Hypertension and chronic kidney disease. Dis Mon 2015; 61: 387-395.

19. Kakizoe Y, Kitamura K, Ko T, Wakida N, Maekawa A, Miyoshi T et al. Aberrant ENaC activation in Dahl salt-sensitive rats. J Hypertens 2009; 27: 1679-1689.

20. Pavlov TS, Levchenko V, O'Connor PM, llatovskaya DV, Palygin O, Mori T et al. Deficiency of renal cortical EGF increases ENaC activity and contributes to salt-sensitive hypertension. $J$ Am Soc Nephrol 2013; 24: 1053-1062.

21. Rizzo F, Staub O. NEDD4-2 and salt-sensitive hypertension. Curr Opin Nephrol Hypertens 2015; 24: 111-116.

22. Dahlberg J, Nilsson LO, von Wowern F, Melander O. Polymorphism in NEDD4L is associated with increased salt sensitivity, reduced levels of P-renin and increased levels of Nt-proANP. PLOS ONE 2007; 2: e432.

23. Russo CJ, Melista E, Cui J, DeStefano AL, Bakris GL, Manolis AJ et al. Association of NEDD4L ubiquitin ligase with essential hypertension. Hypertension 2005; 46 : 488-491.

24. Svensson-Farbom $P$, Wahlstrand B, Almgren $\mathrm{P}$, Dahlberg J, Fava $\mathrm{C}$, Kjeldsen $\mathrm{S}$ et al. A functional variant of the NEDD4L gene is associated with beneficial treatment response with beta-blockers and diuretics in hypertensive patients. J Hypertens 2011; 29: $388-395$

25. McDonough CW, Burbage SE, Duarte JD, Gong Y, Langaee TY, Turner ST et al. Association of variants in NEDD4L with blood pressure response and adverse cardiovascular outcomes in hypertensive patients treated with thiazide diuretics. $J$ Hypertens 2013: 31: 698-704

26. Fouladkou F, Alikhani-Koopaei R, Vogt B, Flores SY, Malbert-Colas L, Lecomte MC et al. A naturally occurring human Nedd4-2 variant displays impaired ENaC regulation in Xenopus laevis oocytes. Am J Physiol Renal Physiol 2004: 287: F550-F561.

27. Hill NR, Fatoba ST, Oke JL, Hirst JA, O'Callaghan CA, Lasserson DS et al. Global Prevalence of chronic kidney disease-a systematic review and meta-analysis. PLOS ONE 2016; 11: e0158765.

28. National Kidney F. K/DOQI clinical practice guidelines for chronic kidney disease: evaluation, classification, and stratification. Am J Kidney Dis 2002; 39(Suppl 1): S1-S266. 
29. Zager RA, Johnson AC, Andress D, Becker K. Progressive endothelin-1 gene activation initiates chronic/end-stage renal disease following experimental ischemic/reperfusion injury. Kidney Int 2013; 84: 703-712.

30. Zoja C, Abbate M, Remuzzi G. Progression of renal injury toward interstitial inflammation and glomerular sclerosis is dependent on abnormal protein filtration. Nephrol Dial Transplant 2015; 30: 706-712.

31. Guo DF, Chenier I, Lavoie JL, Chan JS, Hamet P, Tremblay J et al. Development of hypertension and kidney hypertrophy in transgenic mice overexpressing ARAP1 gene in the kidney. Hypertension 2006; 48: 453-459.

32. Reungjui S, Hu H, Mu W, Roncal CA, Croker BP, Patel JM et al. Thiazide-induced subtle renal injury not observed in states of equivalent hypokalemia. Kidney Int 2007; 72: 1483-1492.

33. Rubera I, Loffing J, Palmer LG, Frindt G, Fowler-Jaeger N, Sauter D et al. Collecting ductspecific gene inactivation of alphaENaC in the mouse kidney does not impair sodium and potassium balance. J Clin Invest 2003; 112: 554-565

34. Konstas AA, Shearwin-Whyatt LM, Fotia AB, Degger B, Riccardi D, Cook DI et al. Regulation of the epithelial sodium channel by N4WBP5A, a novel Nedd4/Nedd4-2-interacting protein. $J$ Biol Chem 2002; 277: 29406-29416.

35. Foot NJ, Gembus KM, Mackenzie K, Kumar S. Ndfip2 is a potential regulator of the iron transporter DMT1 in the liver. Sci Rep 2016; 6: 24045.
36. Feng M, Deerhake ME, Keating R, Thaisz J, Xu L, Tsaih SW et al. Genetic analysis of blood pressure in 8 mouse intercross populations. Hypertension 2009; 54: 802-809.

37. Ronzaud C, Loffing J, Bleich M, Gretz N, Grone HJ, Schutz G et al. Impairment of sodium balance in mice deficient in renal principal cell mineralocorticoid receptor. J Am Soc Nephrol 2007; 18: 1679-1687.

(c) (i) (5) $\odot$ This work is licensed under a Creative Commons Attribution-NonCommercial-NoDerivs 4.0 International License. The images or other third party material in this article are included in the article's Creative Commons license, unless indicated otherwise in the credit line; if the material is not included under the Creative Commons license, users will need to obtain permission from the license holder to reproduce the material. To view a copy of this license, visit http://creativecommons.org/licenses/by-nc-nd/4.0/

(C) The Author(s) 2017

Supplementary Information accompanies this paper on Cell Death and Differentiation website (http://www.nature.com/cdd) 